\title{
MIDIATIZAÇÃO DA SEXUALIDADE: A EMERGÊNCIA \\ DA NARRATIVA CONTRA-HEGEMÔNICA DA ASSEXUALIDADE NO CIBERESPACO
}

\author{
Vitória Carvalho Rocho da Silva* \\ Demétrio de Azeredo Soster**
}

RESUMO

Neste artigo se expõe o resultado do estudo monográfico ${ }^{1}$ sobre a emergência das narrativas contra-hegemônicas no ciberespaço. Por narrativas contra-hegemônicas compreende-se aquelas que são produzidas por grupos que não se sentem representados na mídia ou que criam um discurso que vai de encontro com o que está presente na mídia hegemônica, como é o caso da narrativa da assexualidade. A hipótese que nos moveu é que essa emergência tem lugar em decorrência da processualidade da midiatização e, nela, o ciberespaço. Tratou-se de um estudo de caso, no qual o objeto de estudo teve por recorte dez excertos que nos permitem identificar a evolução da narrativa da assexualidade na mídia, no presente artigo haverá a exposição de dois deles. Palavras-chave: Narrativa; Midiatização; Assexualidade.

\section{INTRODUÇÃO}

Antes de fazermos as considerações iniciais deste artigo de comunicação científica, questiono ao leitor: você sabe o que é assexualidade? Esta foi a pergunta que fiz há cerca de um ano e meio em sala de aula, para colegas e professor. A resposta que obtive foi a falta de conhecimento sobre o assunto. Diante disso, continuei a questionar sobre a assexualidade para amigos e familiares e, logo, para colegas pertencentes ou estudiosos da comunidade LGBTQ+. O resultado foi o mesmo e passei a indagar o motivo desse conhecimento ser comum a mim, porém não à grande parte daqueles que me rodeiam, o que me levou a refazer meu trajeto dentro da comunidade

\footnotetext{
* Universidade de Santa Cruz do Sul. Bacharela em Comunicação Social - habilitação Jornalismo na Universidade de Santa Cruz do Sul. vitoriacrocho@gmail.com .

** Graduação em Jornalismo pela Universidade do Vale do Rio dos Sinos (Unisinos, 1990), mestrado em Comunicação e Informação pela Universidade Federal do Rio Grande do Sul (Ufrgs, 2003) e doutorado em Ciências da Comunicação pela Universidade do Vale do Rio dos Sinos (Unisinos), de São Leopoldo, Rio Grande do Sul. deazeredososter@gmail.com .

1 Disponível em: https://repositorio.unisc.br/jspui/handle/11624/2744.
} 
LGBTQ+ como membro, mas também como observadora. A partir desse caminho, percebi que a mídia foi para mim - e é para muitos - uma peça essencial na descoberta do colorido e abundante universo das sexualidades e gêneros fora do padrão heteronormativo ${ }^{2}$.

A identidade sexual é uma parte importante da vida da maioria das pessoas. Alguns aspectos vêm naturalmente, mas muitos fatores do comportamento sexual são determinados culturalmente. Arquétipos de atratividade, rituais de namoro e expectativas de relacionamento são estipulados pela cultura na qual o indivíduo está inserido. Os comportamentos e padrões sexuais atuais são assimilados pelos jovens à medida que amadurecem. Nas sociedades modernas, a mídia se torna uma importante fornecedora de modelos e normas sexuais e de gênero, assim como as tecnologias de comunicação interativa, tais como redes sociais e comunidades online, também disponibilizam acesso fácil à informação e pessoas que podem apresentar, reforçar ou participar de comportamentos sexuais.

Tendo isso em vista, passamos a pensar academicamente a relação entre mídia e assexualidade. Não há como negar que a sociedade vive um tempo de imersão midiática baseado no avanço tecnológico constante que concretiza o mundo virtual e este, por sua vez, molda o real. Conseguimos desenhar o que é a sociedade midiatizada a partir do ponto que a comunicação é um segmento criado por meio da interação de indivíduos que precisam de técnicas para formar diálogos. Em outras palavras, o ser humano está constantemente buscando seus iguais para suprir suas necessidades físicas e emocionais de forma que os novos aparelhos e modelos de interação foram e continuam sendo construídos para atender primordialidades que ainda não foram remediadas ou que estão surgindo com o avançar dos tempos.

Utilizando uma lógica própria da mídia, que oferta sentido, título e imagem, a assexualidade sai do padrão histórico de construção de narrativas de gênero e sexualidade - antes expressas em formas de manifestações presenciais - e a pesquisa tentou identificar a razão desta discussão estar na rede. A partir da utilização da internet como ferramenta de midiatização e estratégia de colocar os indivíduos publicamente no espaço e tempo, questiona-se: afinal, como acontece a midiatização da assexualidade e a construção de narrativas contra-hegemônicos no ciberespaço?

\footnotetext{
Heteronormatividade é a crença de que a heterossexualidade, baseada na binaridade de gênero, é a norma ou orientação sexual padrão ou seja pressupõe que as relações sexuais e conjugais sejam mais adequadas entre pessoas do sexo oposto. Uma visão "heteronormativa", portanto, envolve o alinhamento de sexo biológico, sexualidade, identidade de gênero e papéis de gênero.
} 
Dessa forma, foi estabelecido um caminho metodológico que permite a percepção de pistas discursivas para responder a essa pergunta, levando em conta, além das teorias que serão discutidas, as abordagens culturais. $\mathrm{O}$ primeiro capítulo teórico da monografia traz uma reflexão sobre o conceito de narrativa no decorrer do tempo e sua relação com a comunicação. Após compreender suas particularidades e relevância, inicia-se um registro de sua importância na formação de identidade - mais precisamente da identidade LGBTQ+ - a partir do que Bruner (2001) chama de narrativas da vida. Por fim, conceitua-se hegemonia e contra-hegemônia, a fim de estabelecer a assexualidade como uma narrativa contra-hegemônica.

O segundo capítulo de teoria insere a midiatização e, a partir dela, a cibercultura. Segundo Fausto Neto (2006), há um novo modelo de interação na sociedade midiatizada que já não é mais estabelecido por laços sociais, mas por ligações sociotécnicas. Ou seja, a midiatização não acontece apenas quando se está produzindo e recebendo informação, acontece também quando comentamos sobre ela, quando tiramos o produto comunicacional do meio e o colocamos no convívio com outras pessoas. A partir desse conceito, a midiatização começa a conversar com o conceito de ciberespaço, que é definido por Pierre Lévy (2000) como um

(...) novo meio de comunicação que surge da interconexão mundial dos computadores. O termo especifica não apenas a infraestrutura material da comunicação digital, mas também o universo oceânico de informações que ela abriga, assim como os seres humanos que navegam e alimentam esse universo (LÉVY, 2000. p. 17).

A partir da consolidação da internet e, consequentemente, da cibercultura, grupos sociais têm se organizado com maior dinâmica e agilidade por meio de sites e comunidades online, fazendo com que a dispersão geográfica não seja um impedimento quando o interesse é comum. No ciberespaço, os indivíduos têm a capacidade de produzir e compartilhar todos os tipos de informação entre seus semelhantes, exercendo os três princípios básicos da sociedade da informação lançados por Lemos (2006): “emitindo, na produção de conteúdo, conectando, em processos coletivos e colaborativos, produzindo inteligências coletivas e alterando as condições de vida, reconfigurando a cultura e a vida social" (LEMOS, 2006, p. 46, grifo nosso). 
Ambas as vertentes de estudo apresentadas possuem forte influência em como a sociedade compreende questões éticas e morais, dentro disso, este trabalho concentra-se na midiatização da assexualidade e busca compreender a importância da mídia e da cibercultura para a emergência e emancipação de narrativas contra-hegemônicas, com foco no exemplo da assexualidade, pois compreende-se que a orientação sexual se expressa no ciberespaço em busca de consolidação.

O terceiro e último capítulo teórico é concentrado no conceito de assexualidade e como sua narrativa está sendo composta. A pessoa que se identifica como assexual experimenta pouca ou nenhuma atração sexual, porém esta definição foi construída gradualmente e ainda hoje sofre questionamentos de seu caráter como orientação sexual. Além da sondagem da sexualidade na mídia, é apresentado um resgate da assexualidade em outros campos de pesquisa, principalmente da psicologia, pois foi a partir desses estudos, juntamente com a popularização da internet, que a assexualidade passou a ser difundida midiaticamente.

Por fim, caso a sua resposta para a pergunta que aparece no início deste excerto tenha sido não, passa-se a ser compreendido o porquê de trabalhos como este serem necessários. A proposta da pesquisa é analisar, pelo viés da teoria da midiatização e do conceito de ciberespaço, a construção da narrativa da assexualidade por meio de canais online que permitem o estudo, a difusão e a validação da mesma como orientação sexual. Desde que a internet abriu espaço para manifestações sociais e individuais, a sociedade não está mais presa ao que a mídia convencional tem como pauta. Com este ambiente, além de expor ideias e opiniões, os indivíduos podem encontrar semelhantes e, assim, criar comunidades, o que permite que particularidades tenham a possibilidade de serem vistas como realidades sociais para além de pequenos grupos. Ou seja, a nova ambiência tecnológica possibilita a construção e fortalecimento de narrativas contra-hegemônicas. A assexualidade é um desses discursos emergentes que buscam validação por meio de estudos e debates online, destacando-se das demais orientações devido ao fato de ser uma das poucas, até então, a surgir exclusivamente nessa nova realidade tecnológica.

\section{METODOLOGIA}

A pesquisa científica baseia-se em encontrar uma solução para um problema específico. Com o intuito de compreender como a midiatização influencia na validação de discursos contra-hegemônicos no ciberespaço por 
meio da narrativa da assexualidade, foi utilizada a estratégia da antimetodologia positiva de Juremir Machado da Silva (2010). Ou seja, parte da ideia de que a relação do pesquisador com o objeto deve adotar os seguintes passos: estranhar, entranhar e desentranhar. Portanto, neste bloco vamos explorar a abordagem metodológica definida no trabalho monográfico e oferecer um método de análise.

O estranhamento — ou seja, a capacidade de descobrir o objeto por intermédio de outras lentes — iniciou-se ainda antes do início da pesquisa, há cerca de três anos. Desde então, a assexualidade tem sido um objeto de interesse da pesquisadora, de forma que a aproximação ocorreu naturalmente e a introdução nos círculos de discussão sobre gênero e sexualidade auxiliaram na descoberta e aprendizado sobre a assexualidade como orientação e narrativa contra-hegemônica. Em 2018, esse interesse tomou forma de reportagem na disciplina de Jornalismo de Revista do curso de Comunicação Social da UNISC, que possibilitou à estudante começar uma pesquisa objetiva sobre o objeto durante a elaboração do texto para a Revista Exceção.

Para a elaboração da reportagem houve a pesquisa de materiais online sobre o tema, desde sites, grupos, organizações e estudos acadêmicos, o que oportunizou arrecadação do material inicial para a pesquisa até então apresentada. Outra parte importante do processo de criação do texto jornalístico foram as entrevistas. Primeiramente, a pesquisadora entrou em contato com duas pessoas que se encontram dentro do espectro assexual - Regina (nome fictício), estudante e Poliana Lazarini, atleta — por intermédio de entrevista por Messenger, a partir do qual foi utilizado suas experiências de descoberta, relacionamento e aceitação como introdução e explicação do que é a assexualidade e suas vertentes. A reportagem também possibilitou a entrevista de dois importantes pesquisadores da assexualidade, Elisabete de Oliveira ${ }^{3}$ e Anthony Bogaert ${ }^{4}$. O primeiro contato foi feito com o professor canadense, em conversa por meio de Skype, de cerca de 35 minutos e, mais tarde, foi realizada a entrevista com a pedagoga brasileira via e-mail. Em ambos foram debatidos tópicos como a aproximação dos pesquisadores com o tema da assexualidade, definições de terminologias dentro da orientação sexual,

Elisabete Regina Baptista De Oliveira, pedagoga, mestre e doutora em Educação pela Faculdade de Educação da USP. Autora da tese "Minha vida de ameba: os scripts sexo-normativos e a construção social das assexualidades na internet e na escola".

4 Anthony Francis Bogaert é um psicólogo canadense e professor nos Departamentos de Psicologia e de Ciências da Saúde Comunitária da Universidade de Brock. Bogaert é conhecido por estudar vários assuntos relacionados à sexualidade humana, incluindo assexualidade. 
estudos acadêmicos na área, a relação entre assexualidade e saúde, classe social e educação, o entendimento da psicologia sobre o que é assexualidade e a presença da mesma na comunidade LGBTQ+. Em relação à AVEN, foi possível entrar em contato com Michael Doré, diretor de mídia da organização, também via Skype em uma conversa com cerca de 30 minutos na qual foi discutido alguns pontos semelhantes aos dos pesquisadores e com o acréscimo de questões sobre a AVEN como comunidade e seu trabalho informativo, a identificação pessoal com a assexualidade e diferenciação entre atração romântica e sexual.

As informações e conhecimento adquiridos durante a produção da reportagem foram essenciais para delimitar a narrativa da assexualidade como objeto de estudo do presente trabalho, no qual foi seguido o segundo passo proposto por Silva (2010), o entranhamento. Para que esse movimento fosse feito, ou seja, inserir-se no objeto para melhor compreendê-lo, foi elaborada uma pesquisa bibliográfica, o que, segundo Lakatos e Marconi (2017), tem como objetivo prover ao pesquisador familiaridade com os materiais já produzidos e publicados do assunto que está sendo trabalhado, pois dessa forma é possível compreender até que ponto o tema já foi explorado e encontrar lacunas que podem ser supridas, ou seja, uma forma de encontrar a delimitação da pesquisa de forma que ela se torne original e necessária para o campo acadêmico, evitando a produção de algo ao qual o problema já tenha tido sua solução encontrada (STUMPF, 2006).

A finalidade da pesquisa bibliográfica é, também, dar ao pesquisador meios de exercer o terceiro passo sugerido por Silva (2010), o desentranhamento, ou seja, possibilita fazer análises e críticas com conhecimento o suficiente para que o resultado se torne relevante. Esse processo se dá "de forma a evidenciar o entendimento do pensamento dos autores, acrescido de suas próprias ideias e opiniões" (STUMPF, 2006, p. 51). Como resultado dessa pesquisa inicial, a pesquisadora esteve apta a organizar ideias lógicas e escolher o melhor modelo de pesquisa a ser seguido a partir do referencial teórico levantado, no caso, utiliza-se o método qualitativo.

A pesquisa qualitativa enfoca a compreensão do objeto com uma abordagem humanista. Enquanto a metodologia quantitativa é baseada em métodos numéricos, a qualitativa é usada para entender as crenças, experiências, atitudes, comportamentos e interações dos e entre os indivíduos, gerando dados não apenas estatísticos. A integração da pesquisa qualitativa em desdobramentos sociais é uma estratégia reconhecida por sua capacidade 
de adicionar uma nova dimensão aos estudos que não podem ser obtidos por meio da medição de variáveis sozinhas.

Dessa forma, concorda-se com Moresi (2003), para quem a pesquisa qualitativa

(...) considera que há uma relação dinâmica entre o mundo real e o sujeito, isto é, um vínculo indissociável entre o mundo objetivo e a subjetividade do sujeito que não pode ser traduzido em números. A interpretação dos fenômenos e a atribuição de significados são básicas no processo de pesquisa qualitativa. Não requer o uso de métodos e técnicas estatísticas. O ambiente natural é a fonte direta para coleta de dados e o pesquisador é o instrumento-chave. É descritiva. Os pesquisadores tendem a analisar seus dados indutivamente. $O$ processo e seu significado são os focos principais de abordagem (MORESI, 2003, p. 8-9).

Portanto, o método qualitativo é principalmente exploratório. Ele é usado para obter uma compreensão das razões, opiniões e motivações subjacentes, fornecendo discernimento sobre o problema ou ajudando a desenvolver ideias ou hipóteses para um resultado potencial. Para tentar entender como as narrativas contra-hegemônicas de assexualidade se colocam na mídia, circunscreve-se, dentro da pesquisa qualitativa, e do ponto de vista metodológico, os excertos do objeto de pesquisa com o estudo de caso, que foi selecionado por ser um método de exploração imersivo de realidades, apresentando natureza investigativa.

Dessa forma, concordamos com Yin (2005), que define o estudo de caso como ferramenta para análise é de relevância para estudos em ciências humanas, pois possibilita ao pesquisador se aprofundar no objeto de estudo ao passo que o permite considerar um universo maior de variáveis. O estudo de caso fornece interpretações, descrições e comparações que contribuem para o esclarecimento de questões pendentes e provocações temáticas. Este modelo pretende auxiliar no esclarecimento do fenômeno que interliga a emergência das narrativas contra-hegemônicas com o "novo" modo de comunicação: o ciberespaço.

Para o estudo monográfico, os excertos foram organizados em cinco categorias, a partir das quais foram selecionados dez excertos, suas referências e descrições. As categorias são: programa de televisão, matéria online, ilustração, vídeo em plataforma online e glossário. No presente artigo, iremos explorar apenas uma delas, a matéria online, mais especificamente jornalística, que 
pode ser uma notícia, artigo ou reportagem de não-ficção, sobre um tópico específico, formando uma parte independente de uma publicação impressa ou digital, como um jornal ou revista. No caso de publicações online, refere-se a qualquer texto informativo criado com e destinado à visualização em um computador, smartphone ou dispositivo digital similar. Os formatos de escrita online incluem mensagens de texto, mensagens instantâneas, e-mail, blog e postagem e comentários em sites de mídia social.

Feita a definição de como foram selecionados e separados os excertos para análise, no próximo bloco trazê-se dois excertos para compreender a trajetória das manifestações da narrativa da assexualidade por meio da mídia online com o avançar do tempo, focando na orientação sexual como exemplo de uma narrativa contra-hegemônica que ganhou espaço e visibilidade no ciberespaço, tendo em vista o momento atual no qual a cibercultura faz com que as relações virtuais sejam tão presentes e relevantes em causas como esta e outras.

\section{PISTAS DISCURSIVAS}

Feito o caminho de pesquisa e metodologia apresentado até este ponto, é chegada a hora de analisar o objeto de estudo. Uma suposição relacionada ao comportamento humano face à libido é que a sexualidade não é algo que simplesmente se faz, mas uma identidade, algo que se é (Weeks, 2007; Foucault, 1979). Enquanto estudiosos da sexualidade teorizaram as construções sociais da identidade sexual, pretendeu-se, na análise, apresentar pistas discursivas para destacar momentos nos quais a assexualidade obteve destaque na mídia, oferecendo a narrativa da orientação e apontando sua emergência. Indivíduos que se identificam como assexuais desafiam as noções comerciais e sociais que sexo é inerente do ser humano e a base para um relacionamento saudável e apresentam uma oportunidade única de explorar a negociação de identidade e desejo.

A assexualidade, uma orientação sexual de narrativa contra-hegemônica e emergente, está sendo abordada dentro do quadro teórico da midiatização e por meio das tecnologias da internet que permitiram a formação da comunidade por indivíduos isolados geograficamente. Enquanto os cientistas sociais conceituam seus interesses na sexualidade de três maneiras comuns - comportamento, desejo e identidade — neste estudo, escolhemos concentrar na relação entre mídia e assexualidade, o que influencia na formação identitária dessa comunidade. No artigo explicitamos apenas uma categoria analisada para visualização do objeto, sendo esta a de matérias online. 
Enquanto veículos de comunicação estavam se adaptando a ideia da existência da assexualidade e diversas matérias televisivas e em jornais estavam ainda a questionando como orientação, The New York Times publicou em 09 de junho de 2005 uma reportagem exploratória e bastante completa sobre a assexualidade sua versão online e impressa, selecionada como excerto $\mathbf{9}^{5}$. Sob o título "For Them, Just Saying No Is Easy", a jornalista Mary Duenwald inicia o texto a sentença: "Birds do it, bees do it. But not necessarily all of them", fazendo uma referência a uma expressão idiomática do idioma inglês e eufemismo que se refere ao namoro e às relações sexuais, em seguida ela uso exemplos de animais que não tem a prática sexual em seu curso natural para fazer uma ligação deveras duvidosa com os assexuais. Logo ela usa a frase "condição normal" para descrever a assexualidade, o que reflete algo externo ou anormal, porém é assertiva ao continuar que a assexualidade "is not the result of confused sexual orientation, a fear of intimacy or a temporary lapse of desire".

A reportagem foi lançada após os estudos de Bogaert, o que causou uma onda de veículos de comunicação usarem a assexualidade como pauta. Nesse período, poucos estudos haviam sido feitos na área e a maior parte dos estudiosos da sexualidade desconheciam o tema ou o negavam. Um das fontes da matéria, Irwin Goldstein, diretor do Centro de Medicina Sexual da Universidade de Boston e editor The Journal of Sexual Medicine, aproxima-se de fazer isso ao dizer que três quartos de seus pacientes não possuíam desejo sexual, diagnosticando-os com Transtorno do Desejo Sexual Hipoativo (TDSH). Porém, logo adiciona que esse é o caso apenas quando a falta de interesse no sexo causa sofrimento ou leva a conflitos dentro de um casamento ou relacionamento romântico. Mesmo que o último detalhe não seja relevante dentro da psicologia particular, mas da concepção de relacionamento na sociedade, é um comentário progressista entre profissionais da psicologia da época.

Um exemplo é dado quando a reportagem abre espaço para Leonard R. Derogatis, psicólogo e diretor do Centro de Saúde e Medicina Sexual da Universidade Johns Hopkin, que discorda que a falta de interesse em sexo pode ser considerada normal e compara o desejo sexual com o apetite por comida, declarando que "sex is a natural drive, as natural as the drive for sustenance and water to survive. It's a little difficult to judge these folks as normal".

Disponível em: https://www.nytimes.com/2005/06/09/fashion/thursdaystyles/for-them-just-saying-no-is-easy.html. 
Na parte seguinte, a reportagem faz uma breve distinção entre assexual e assexuado e atração romântica e sexual, ambas em um discurso vago e indireto, quase tentando fazer humor ao exemplificar a reprodução assexual com amebas e águas-vivas. A AVEN é o próximo tópico explorado por Duenwald, que descreve a organização como "grupo da internet", mesmo que já fosse a maior comunidade onlines a trabalhar com a assexualidade. A jornalista traz o dado que o site conta com cerca de 4 mil participantes registrados, enquanto em 2018, em entrevista para a reportagem citada anteriormente, Michael Doré, diretor de mídia da AVEN, afirma que a organização possui uma adesão internacional de quase 70 mil pessoas, recebendo cerca de 35 novos membros diariamente, continuando como a maior organização de assexualidade do mundo.

O próximo bloco traz informações de tronco comum com as demais matérias apresentadas na análise. Comparação com celibato, o dado de 1,1\% das pessoas serem assexuais analisado por Bogaert e identificação enganosa com outras sexualidades antes de chegar a assexualidade são temas que aparecem em praticamente todos os materiais produzidos sobre a assexualidade. Porém, a reportagem abre espaço para uma conversa sobre as causas fisiológicas e psicológicas da assexualidade, sugerindo, inclusive, tratamentos hormonais. Tal discussão foi perdendo intensidade por meio de estudos e vozes que que se manifestaram com o passar do tempo, mas em 2005 ainda era um debate válido e fortemente ligado às ciências da natureza.

A reportagem, como um todo, é satisfatória, ainda que apresente certas visões ou formas de lidar com a assexualidade que atualmente são consideradas ofensivas ou constrangedoras. Oferece uma base informativa abundante, um número de fontes elevado comparado às demais matérias produzidas na mesma época com seis cases e sete especialistas entre psicólogos, médicos, escritores e pesquisadores e passa a mensagem de que, considerando a publicidade generalizada de medicamentos e cosméticos para melhorar o desempenho sexual e a onipresença de referências sexuais na cultura pop, não é de surpreender que aqueles que não professam desejo sexual tenham sido mal compreendidos ou pelo menos esquecido, porém, a matéria revitaliza a importância de ver a assexualidade para além disso.

Sete anos após a reportagem do New York Times, foi a vez do Observer - jornal dominical do grupo The Guardian - produzir uma matéria de relevância com a pauta assexual, nosso excerto $1^{6}$. Em 26 de fevereiro de 
2012, a editora de notícias sênior do jornal britânico, Rosie Swash, publicou o texto "Among the asexuals", o qual começa de forma divertida com o depoimento de uma fonte assexual. "I am 47 but look younger, probably because I take good care of myself and also do not have the stress of a husband and kids", inicia Annette antes de falar sobre sua vida no subúrbio de Minnesota, seu cotidiano como advogada e as experiências de ser uma mulher solteira e assexual - o que envolve, inclusive, uma anedota sobre a vizinha que rezou para que ela conseguisse um marido.

O começo da matéria é pessoal e leve, diferente do modo como a assexualidade é abordada nos demais textos e vídeos exploratórios que buscam sempre iniciar com a definição da orientação ou as dificuldades de ser assexual com um discurso pessimista. Já Swash apresenta um caso de uma assexual bem resolvida consigo mesma e que possui uma crítica maior sobre como as pessoas preferem falar — negativamente, na maioria das vezes sobre seus cônjuges do que sobre assuntos sociais de interesse comum como política e educação.

No bloco seguinte, David Jay e a AVEN tornaram-se foco da reportagem, como de costume. A jornalista levanta o dado de que a comunidade, em 2012, possuía cerca de 50 mil membros — sendo que em 2005 o registro era de 4 mil e, em 2018, a AVEN contava com mais de 70 mil associados. Em seguida, pontua os obstáculos cotidianos enfrentados pelos assexuais em uma sociedade centralizada em relações sexuais e românticas e desinformada quanto à orientação, trazendo exemplo da presença de Jay no programa de televisão The View e demonstrando como as apresentadoras lidaram ofensivamente com a questão. A jornalista utiliza uma fala de Bogaert para finalizar essa crítica: "Theoretically the absence of sexual desire shouldn't be a problem, but ours is a media which suggests hypersexuality is the norm", ou seja, potencialmente, a assexualidade se tornou um 'problema' à medida que se tornou mais visível.

Em um longo trecho, Swash responde algumas perguntas instintivas relacionadas à comunidade assexual, desde os diferentes tipos de atração, as etapas de descoberta até o confronto com celibato e traumas. Apoiando em pesquisas científicas, a jornalista deixa claro que a assexualidade não é sinônimo de deficiência física ou psíquica. É interessante ressaltar que a própria Swash admite ter sido desrespeitosa com uma de suas fontes ao questioná-lo se sua religião era o motivo da assexualidade. "I would never ask a gay person whether their upbringing had made them gay, so why does it trip off the 
tongue when talking to an asexual person?", escreveu ao compreender que assexuais não têm necessariamente um problema em serem assexuais, mas sim com a suposição de que isso é "causado". A reportagem, além de informativa com seus cinco cases e cinco especialistas, é compreensiva. Por meio da escrita de Rosie Swash é possível acompanhar o processo que faz jus ao título da matéria enquanto ela caminha entre assexuais e não apenas expõe o público uma realidade distinta da deles, mas também demonstra as descobertas pessoais da própria jornalista. Em conclusão, percebe-se que qualquer elemento que vá contra a norma e ameace o status quo é ridicularizado ou alvo para eliminação. As reações com as quais as pessoas assexuais têm de lidar mostram quão tacanha e desinformada sobre sexo que a sociedade realmente é.

\section{CONSIDERACOOES FINAIS}

Compreender os principais aspectos da modernidade, como individualização, democratização, sexualização e mercantilização, é crucial para o entendimento das culturas e da emergência de narrativas dentro delas. Como foi demonstrado no trabalho, tais fatores são relevantes para a exploração da relação entre mídia, mudança social e sexualidade. Para investigar essas transformações, os estudiosos se referiram principalmente às mudanças visíveis nos textos da mídia: como a sexualidade é atualmente representada e como foi representada nas últimas décadas no contexto da mídia produzida em larga escala e da cultura popular.

No diálogo entre narrativa, midiatização e cibercultura, compreende-se que a estrutura sócio-técnico-discursiva presente na nova ambiência midiática reconfigura lugares. Consequentemente, as ideologias dominantes produzidas pelas indústrias comunicacionais tornaram-se cada vez mais entrelaçadas com as subjetividades nas quais confiamos para produzir nossas próprias identidades. Os aspectos tecnológicos de reconfiguração de mundo próprios da midiatização estão sendo refletidos na importância da comunicação midiática na vida sexual cotidiana das pessoas. Percebemos, por fim, a mídia como co-construtora de subjetividades e identidades, sendo este um processo contínuo.

Os estudos da formação cultural por intermédio da mídia têm sido importantes para explicar como nossas identificações com a cultura popular se relacionam com nossas identidades, sendo o público considerado um ator ativo, negociando com os produtos midiáticos ou desenvolvendo formas para tornar esses produtos seus. Do ponto de vista estrutural, compreendemos que a emergência na narrativa da assexualidade vai além de uma bandeira 
que está sendo erguida, mas representa diversas outras narrativas contra-hegemônicas que utilizam da midiatização e do ciberespaço para se fazerem válidas. Comunidades originadas nas mídias sociais são vistas como alternativa aos significados produzidos na mídia tradicional, ao passo que buscam reconhecimento e fazer parte natural da hegemonia.

Os estudos aqui apresentados não se resumem apenas em dar sentido às representações produzidas pela mídia, as pesquisas dessas áreas são muito mais complexas, pois a comunicação midiática é vivida no cotidiano e afeta cada vez mais a construção da realidade. Por isso a escolha da midiatização como conceito usado para analisar criticamente a inter-relação entre mudanças na mídia e nas comunicações, assim como as transformações na cultura e na sociedade. Nesse nível, a midiatização tem dimensões quantitativas e qualitativas. No que diz respeito aos aspectos quantitativos, a midiatização refere-se à crescente expansão temporal, espacial e social da comunicação mediada. Já quanto aos aspectos qualitativos, a midiatização refere-se à especificidade de certas mídias na mudança sociocultural: importa que tipo de mídia é usada para que tipo de comunicação.

Argumentamos neste trabalho que o papel da mídia e da comunicação na construção da identidade sexual das pessoas necessita maior visibilidade. Embora estudiosos e comentaristas tenham fornecido informações sobre como a sexualidade é representada na mídia, sabemos pouco sobre o papel atual e passado das instituições e práticas midiáticas nas sexualidades cotidianas das pessoas e em políticas sexuais mais amplas. Podemos dizer que isso se dá ao fato de que atores contra-hegemônicos são frequentemente fragmentados. Consequentemente, grupos dispersos não aumentam as pressões para desafiar efetivamente o discurso hegemônico. Acreditamos que é importante que o antagonismo político entre práticas hegemônicas e contra-hegemônicas seja explicado e cultivado, enfatizando a necessidade de promover um movimento contra-hegemônico unificado que possa desenvolver pressões eficazes para desafiar a lógica dominante, estudar sobre ela e ser incorporada.

Dessa forma, enquanto David Jay diz em entrevistas que o "movimento de assexualidade" está em sua terceira fase, nós discordamos. A primeira fase começou no início dos anos 2000, o que não significa que a assexualidade não existia antes, porém não havia uma identidade pública coerente. Tratava-se de identificar exatamente o que era assexualidade — não a supressão do desejo sexual, que é o celibato, mas a ausência dele — enquanto a internet facilitava a aproximação de indivíduos assexuais até a criação de comunidades. 
A segunda fase envolveu mobilização. Em 2006, David Jay se tornou a imagem da representatividade assexual, aparecendo em diversos programas de televisão e sendo fonte para materiais digitais e impressos. As pessoas estavam curiosas, mas a resposta foi impetuosa e superficial, similar a que analisamos no excerto 3. Em 2012, a fase três do movimento da assexualidade teria começado e seria sobre desafiar a noção dominante do que constitui um desejo sexual normal. E, a partir desse ponto, discordamos da teoria de Jay, pois não percebemos a possibilidade de estarmos em um estágio em que as principais premissas sobre assexualidade estão a ponto de alterar a percepção social sobre a sexualidade de modo geral, enquanto a maioria da população está apenas vagamente consciente de sua existência.

A investigação da identidade assexual se torna relevante a partir desse ponto de vista, pois os pesquisadores que exploraram a orientação a abordaram principalmente como um comportamento (falta de atos sexuais) ou um desejo (falta de desejo por atos sexuais) e não deram foco à identidade que está sendo criada, refletindo os demais movimentos contra-hegemônicos que se encontram em grande parte ausentes da literatura acadêmica da comunicação.

Concluímos que a identidade não é apenas um processo introspectivo, mas ganha significado pelas compreensões culturais mais amplas dessa identidade e a conexão entre o indivíduo e a comunidade. No caso dos assexuais, uma dessas conexões é a experiência social histórica e contemporânea ligada às instituições de saúde mental e física. A identidade assexual não apenas reflete um processo individual ou isolado, mas conecta a experiência de chegar a uma identidade com outras pessoas, o que, por sua vez, pode motivar ações sociais e políticas semelhantes a outras narrativas contra-hegemônicas.

Ainda serão necessárias muitas pesquisas em torno das narrativas contra-hegemônicas e suas ascensões, porém, com base na análise que fizemos nste artigo, podemos dizer pontualmente que a emergência da narrativa da assexualidade indica uma nova estrutura de mundo, na qual comunicação e identidade caminham lado a lado, mais próximas do que nunca. E os efeitos dessa relação, se bem compreendida e otimizada, podem trazer unidade e transformação, não só nas questões sexuais, mas em todas as áreas da vida. Pensa-se na possibilidade da emergência de narrativas não hegemônicas em políticas públicas, sistemas de governo, modelos econômicos e de exploração ambiental, as possibilidades são inúmeras e abrem não apenas uma vertente de pesquisa acadêmica, mas uma forma coesa de reconfiguração na forma como compreendemos o mundo. 


\section{REFERÊENCIAS}

BRUNER, Jerome. Self-making and world-making. In: BROCKMEIER, J.; CARBAUGH, D. (Orgs.). Narrative and identity: studies in autobiography, self and culture. John Benjamins Publishing. 2001. p. 25-37. Disponível em:<http://armytage.net/pdsdata/[Jens_Brockmeier,_Donal_A._Carbaugh]_Narrative _and(Book4You).pdf>. Acesso em: 20 mar. 2021.

FAUSTO NETO, Antônio. Midiatização, prática social - Prática de sentido. In: $15^{\circ}$ Encontro Anual da Compós, Anais [...] UNESP-Bauru, 2006. Disponível em: < http://www.compos.org.br/data/biblioteca_544.pdf>. Acesso em: 20 mar. 2021.

FOUCAULT, Michel. A História da Sexualidade. In: Microfísica do poder. Rio de Janeiro: Graal, 1979. p. 243-276.

LAKATOS, E. M.; MARCONI, M. A. Fundamentos de metodologia científica. 8. ed. São Paulo: Atlas, 2017.

LEMOS, André. Cibercultura como território recombinante. In: Evento "Territórios Recombinantes", Instituto Goethe (ICBA), Salvador, 2006. Disponível em: < https://edumidiascomunidadesurda.files. wordpress.com/2016/05/andrc3a9-lemos-ci bercultura-como-territc3b3rio-recombinante.pdf $>$. Acesso em: 20 mar. 2021.

LÉVY, Pierre. Cibercultura. 2. ed. São Paulo: Ed. 34, 2000.

MORESI, Eduardo. Metodologia da Pesquisa. 2003. Disponível em: < https://www.passeidireto.com/ arquivo/56327539/moresi-2003>. Acesso em: 20 mar. 2021.

SILVA, Juremir Machado da. O que pesquisar quer dizer: como fazer textos acadêmicos sem medo da ABNT e da CAPES. Porto Alegre: Sulina, 2010.

STUMPF, Ida Regina C. Pesquisa bibliográfica. In: DUARTE, J.; BARROS, A. (Org.). Métodos e técnicas de pesquisa em comunicação. 2. ed. São Paulo: Atlas, 2006. p. 51-61.

WEEKS, Jeffrey. The remaking of erotic and intimate life. Politca y Sociedad, v. 46, n. 1, p. 13-25, 2009. Disponível em: <https://www.researchgate.net/publication/228348861_The_remaking_of_erotic_and _intimate_life >. Acesso em: 20 mar. 2021.

YIN, Robert K. Estudo de caso: planejamento e métodos. 3. ed. Porto Alegre: Bookman, 2005. 